\title{
A Game-Theoretic Model for Generation Expansion Planning: Problem Formulation and Numerical Comparisons
}

\author{
Angela S. Chuang, Member, IEEE, Felix Wu, Fellow, IEEE, and Pravin Varaiya, Fellow, IEEE
}

\begin{abstract}
This paper presents an application of noncooperative game theory to generation expansion planning (GEP) in a competitive electricity industry. We apply the Cournot model of oligopoly behavior to formulate a GEP model that may characterize expansion planning in a competitive regime, particularly in pool-dominated generation supply industries. Numerical experiments are conducted on a test system to analyze generation investment and market participation decisions of candidate expansion units that vary in costs and forced outage rates. The numerical results point to: 1) greater industry expansion and system reliability, under Cournot competition than under centralized expansion planning; and 2) higher probabilistic measures of reliability from multi-player expansion than from expansion by a traditional monopolist with an equivalent reserve margin requirement. Furthermore, we summarize analytical results involving a simplified version of the GEP game.
\end{abstract}

Index Terms-Economics, game theory, genetic algorithms, power generation planning, power generation reliability, power industry.

\section{INTRODUCTION}

$\mathbf{T}$ HE ELECTRIC power industry in the United States is being restructured with the passage of recent regulation by the Federal Energy Regulatory Commission (FERC). Several states have proposed plans to restructure the industry within their geographic regions. While the transmission system continues to be regulated, generation supply is being opened to competition. Competition in the generation supply industry will fundamentally alter the way generation expansion planning (GEP) is conducted.

This paper describes an application of Cournot theory of oligopoly to model GEP in a competitive electric power industry. Our expansion planning model differs from the classic Cournot model in that it incorporates operational considerations such as plant capacity limitations and energy balance constraints. Similarly to [9], Cournot style competition is employed to model the behavior of competing generation expansion firms. However, unlike previous work we consider separate markets for capacity reserve and energy products. Our method for determining price outcomes is patterned after the basic design of the California ISO/PX System, which relies on auction markets. Furthermore, a major focus of our investigation, absent in [9], is to examine

Manuscript received May 31, 2000. This work was supported by a Robert M. Noyce Foundation Fellowship and by ARO/EPRI Contract WO8333-04.

The authors are with the Department of Electrical Engineering and Computer Science, University of California, Berkeley, Berkeley, CA, USA.

Publisher Item Identifier S 0885-8950(01)09448-2. implications of competition on generation system reliability in terms of adequacy. Through numerical simulation effects of different scenarios of competition on system expansion and reliability are analyzed.

Section II discusses traditional practices and identifies ways competition alters GEP. Section III reviews the classic Cournot model and its applicability in modeling expansion planning. Section IV presents a mathematical formulation of GEP that may characterize expansion planning in a competitive generation industry with multiple markets and multiple players. Decision variables include expansion size and amount of capacity to devote to supplying reserves. Numerical results are presented in Section V, while analytical results from previous work are summarized in Section VI.

\section{Changes in ExPansion Planning}

Generation expansion planning has historically addressed the problem of identifying ideal technology, expansion size, siting, and timing of construction of new plant capacity in an economic fashion and in a manner that ensures installed capacity adequately meets projected demand growth [5]. However, deregulation alters traditional GEP assumptions, models, and methods. Whereas traditional utility practice involves solving centralized planning programs that identify cost-minimizing plans for the utility, under competition multiple firms individually make investment plans intended to maximize profit. Other anticipated changes from competition include: 1) shortened planning horizons due to the elimination of traditional guaranteed return on investment; and 2) the advent of strategic interaction and gaming among firms involved in the generation planning process. That is, competition will cause firms to face higher risks and thus seek quicker returns, and cause decisions of firms to mutually affect other firms' profits and decisions.

Despite opening up to competition, the generation supply industry will not likely, if at all, make an immediate jump to a purely competitive structure. The industry has historically been comprised of a limited number of firms. Thus, we expect a deregulated generation supply industry to take on an oligopolistic structure, that may persist depending on future technological advancement and economics of generation.

\section{Cournot Model}

The Cournot Model of oligopoly competition was introduced by Augustin Cournot in 1838 [4]. The model has become a 
classic in microeconomic oligopoly theory. Cournot games have the following characteristics in common:

- competition occurs only in quantities

- product is nonstorable

- product is homogeneous

- market price is determined by auction

- no entry occurs during the game

- decision-making by players occurs simultaneously.

In the Cournot model, each firm chooses an output quantity to maximize profit. Firms are assumed to produce homogeneous goods that are nonstorable. So all quantities produced are immediately sold. Market price in the model is determined through an auction process that equates industry supply with aggregate demand. Examples of Cournot style auction-based pricing can be found in organized markets such as those for agricultural products like wheat, corn, and rice. The model also assumes that all firms in the industry can be identified at the start of the game, and that decision-making by firms occurs simultaneously. The extent these assumptions are compatible with GEP is discussed below.

There are many striking similarities between the classic Cournot model and the nature of competitive generation markets. In expansion planning firms must decide on how much capacity to expand, a decision variable in quantities. ${ }^{1}$ Also, the assumption that products are nonstorable applies well to the primary products of competitive generation markets, energy and capacity. Furthermore, in pool-dominated generation markets (e.g., California ISO/PX system, former British Power Pool, etc.) prices are primarily determined from auctions and within each auction products are homogeneous. So although there may be product differentiation across various generation markets, products are homogeneous within each auction market.

The nonentry assumption of the Cournot model is to some extent compatible with GEP. Generally, the longer the planning period under examination the greater the likeliness of overlooking a new entrant. But competition is inducing shorter planning horizons. Investors now seek quicker pay-back from investments than have regulated electric utilities. Moreover, for the games defined in this paper in which designated players are existing technologies, nonentry of new players (i.e., viable new technologies) is a reasonable assumption over relatively long periods of time.

In reality, simultaneous decision-making is not generally descriptive of how firms make investment decisions. Nevertheless, our capacity investment model assumes simultaneous decision-making among generation investors, in order to give no player a first mover advantage. This enables us to study expansion outcomes under conditions in which generating units can be compared according to their cost and other characteristics. Such a study may lead to some interesting comparisons among technologies.

Once a game is formulated, outcome predictions are sought. Outcomes of Cournot games are called Cournot equilibria. A Cournot equilibrium is a vector of output quantities that

\footnotetext{
${ }^{1}$ There exist price decisions too in GEP. However, in pool-dominated generation industries in which prices are determined after capacity decisions are made, GEP can be modeled as a two-stage quantity and price game. Such a game reduces to a Cournot game in quantities [7].
}

maximizes the profit of each firm given all other firms' quantity decisions. In mathematical terms, a Cournot equilibrium is a vector $\left(q_{1}^{*}, q_{2}^{*}, \ldots, q_{N}^{*}\right)$ which solves a collection of profit maximization problems of the form:

$$
\max _{q_{i}} \pi_{i}\left(q_{1}^{*}, q_{2}^{*}, \ldots, q_{i}, \ldots, q_{N}^{*}\right) \quad \forall i
$$

where $q_{i}$ is any nonnegative quantity and $\pi_{i}$ is the profit of player $i . N$ is the total number of players in the game. We henceforth denote total industry production by $Q=\sum_{i} q_{i}$, so that $p(Q)$ represents market price. Thus player $i$ 's profit from a product can be represented by $\pi_{i}(q)=p(Q) \cdot q_{i}-c_{i}\left(q_{i}\right)$, where $q$ denotes the vector of production quantities; $c_{i}(\cdot)$ is $i$ 's production cost curve; and $p(\cdot)$ is the inverse demand curve for the product.

\section{EXPANSION PlanNING GAME}

\section{A. Scope and Assumptions}

We present an analytical formulation of the generation planning process involving decisions on new plant construction at a single point in time with multiple technology options available. Players in our proposed game are candidate expansion units-any viable plant technology considered for construction. For example, players may be coal-fired, oil-fired, nuclear, and gas turbine units or plant technologies of any other classification.

In our proposed game, we assume a market structure patterned after the California ISO/PX system. In particular, we consider a single power exchange that facilitates buying and selling of energy through auctions, much like the California Power Exchange. Separate markets for energy and capacity reserves are modeled. Also, we model a real-time energy balancing market which is supplied by real-time energy bids and winning reserve bids. For simplicity, no bilateral energy sales are considered. However, we do consider long-term contracts for reserves that are procured by the ISO at a pre-established price.

Participation in each market and market outcomes art determined as follows. Each player individually decides on its capacity reserve participation level. Quantity-wise, we assume generating units fully bid their unreserved capacity first into the energy market, and then subsequently bid all capacity rejected by the energy market and all contracted capacity reserves into the real-time market. Price-wise, participants are assumed to bid marginal costs. ${ }^{2}$ Outcomes of auctions consist of clearing prices and production schedules specifying the amount of production from each unit. A generator receives production payments at the market clearing price of the auction in which its bids succeed.

\section{B. Problem Formulation}

We define the following variables.

$M C P_{t}$ : fuel cost of marginal unit in energy market at time $t$ $R T P_{t}$ : fuel cost of marginal unit in real time market at $t$ $L_{t}: \quad$ load at time $t$

${ }^{2}$ The marginal cost bidding assumption is reasonable when players are single generating units acting alone in competition with other generators, as opposed to owners of multiple units who can use their generation portfolios to strategize bids. 


$$
\begin{array}{ll}
e_{t i}: & \text { energy production commitment of unit } i \text { at time } t \\
r_{t i}: & \text { real-time production of unit } i \text { at time } t \\
x_{c i}: & \text { generation capacity expansion decision of unit } i \\
x_{o i}: & \text { capacity reservation decision of unit } i \\
X_{o}: & \text { industry capacity reserve offering } \\
p_{i}: & \text { forced outage rate of unit } i \\
C_{0}: & \text { total capacity of existing system } \\
E L D C_{0}: & \text { equivalent load duration curve of initial system } \\
a: & \text { system-wide average customer outage cost } \\
T: & \text { time duration of planning period. }
\end{array}
$$

Profit is the difference between revenues earned and costs incurred from providing electric service. Revenues consist of energy and real-time auction market payments and contracted reserve payments. Expenses include operating costs, capital investment costs, and outage costs. Let $\pi_{i}\left(x_{c i}, x_{o i}\right)$ represent the profit earned by a generating unit indexed by $i$, of size $x_{c i} \mathrm{MW}$, that devotes $x_{o i} \mathrm{MW}$ of its capacity to supplying reserves. Unit $i$ 's profit function is then $\pi_{i}\left(x_{c i}, x_{o i}\right)=\mathrm{R}_{i}\left(\boldsymbol{x}_{\boldsymbol{c}}, \boldsymbol{x}_{o}\right)+\mathrm{P}\left(X_{o}\right)$. $x_{o i}-\mathrm{F}_{i}\left(\boldsymbol{x}_{\boldsymbol{c}}, \boldsymbol{x}_{o}\right)-C_{i}\left(x_{c i}\right)-\mathrm{O}_{i}\left(\boldsymbol{x}_{\boldsymbol{c}}, \boldsymbol{x}_{\boldsymbol{o}}\right)$ where $\boldsymbol{x}_{\boldsymbol{c}}$ is the capacity expansion vector comprised of all players' decisions; $\boldsymbol{x}_{\boldsymbol{o}}$ is the capacity reserve vector; and $\mathrm{P}\left(X_{0}\right)$ is the price of contracted reserves as a function of industry reserve offering. $R_{i}(\cdot)$ represents unit $i$ 's revenue from energy and real-time market production; $\mathrm{F}_{i}(\cdot)$ is unit $i$ 's production cost; $\mathrm{C}_{i}(\cdot)$ is $i$ 's annualized capital investment cost; and $\mathrm{O}_{i}(\cdot)$ is $i$ 's outage cost. Whereas production and capital investment costs are traditional components in generation planning, the other components are additional considerations. Consequently, they are detailed in (1)-(3). The origins of Equation (2) is discussed in [3].

$$
\begin{aligned}
\mathrm{R}_{i}\left(\boldsymbol{x}_{\boldsymbol{c}}, x_{\boldsymbol{o}}\right) & =\sum_{t=1}^{T} M C P_{t} \cdot e_{t i}+\sum_{t=1}^{T} R T P_{t} \cdot r_{t i} \\
\mathrm{P}\left(X_{o}\right) \cdot x_{o i} & =T \cdot(1-p) \cdot E L D C_{0}\left(C_{0}+X_{o}\right) \cdot a \cdot x_{o i} \\
\mathrm{O}_{i}\left(\boldsymbol{x}_{\boldsymbol{c}}, x_{\boldsymbol{o}}\right) & =\sum_{t=1}^{T} R T P_{t} \cdot p_{i} \cdot\left(e_{t i}+r_{t i}\right) .
\end{aligned}
$$

Based on the definitions and profit function previously described, a player's expansion planning problem can be formulated as the following mathematical program.

$$
\begin{aligned}
& \max _{x_{c i}, x_{o i}} \pi_{i}\left(\boldsymbol{x}_{\boldsymbol{c}}, \boldsymbol{x}_{\boldsymbol{o}}\right) \\
& \text { s.t. } 0 \leq x_{o i} \leq x_{c i} \\
& e_{t i} \leq x_{c i}-x_{o i} \quad \forall t \\
& \sum_{i} e_{t i} \leq L_{t} \quad \forall t \\
& r_{t i} \leq x_{c i}-e_{t i} \quad \forall t \\
& \sum_{i} r_{t i} \leq \sum_{i} p_{i} \cdot e_{t i} \quad \forall t .
\end{aligned}
$$

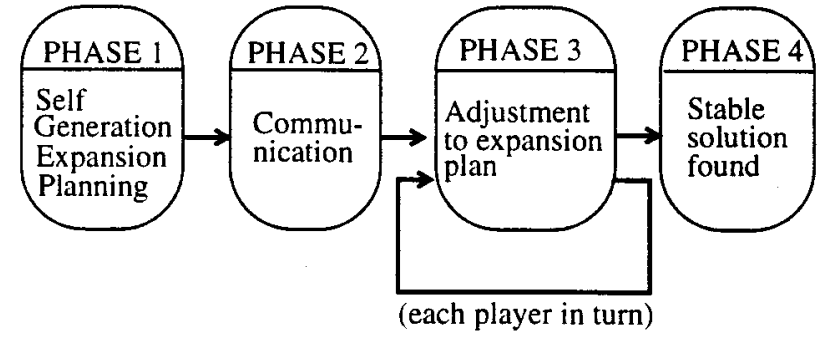

Fig. 1. A four-phase description of the cournot solution algorithm.

Each player seeks to maximize its profit subject to operational and physical constraints. Constraint (4) prevents a unit's capacity reserve commitment from exceeding its capacity rating. Constraint sets (5) and (7) are production constraints limiting participation in the energy and real-time markets according to resource availability of a unit at any given time. The former constraint set limits the amount of capacity a unit can supply in the energy market to its plant capacity minus its contracted reserve commitment. Similarly, the latter constraint set prevents the amount of capacity a unit supplies in the real-time market from exceeding the amount available after discounting energy market commitments. Constraint sets (6) and (8) are analogous to energy balance constraints in the energy and real-time markets, respectively. In the program formulation above, demand in the energy market and demand in the real-time market are assumed to be inelastic. So constraints (6) and (8) take the form of inequality constraints. ${ }^{3}$

\section{Solution Algorithm}

For the generation expansion planning game described, we find Cournot equilibria by using an iterative search procedure. The solution algorithm executes at two levels. At the bottom level, each player maximizes its profit one by one in turn with all other players' actions fixed. At the top level, the algorithm searches for a Cournot equilibrium solution to the overall game. A vector of player decisions for which no player changes its plan after an entire round of optimization among all players is a Cournot equilibrium. The top level of the algorithm iterates until such an equilibrium is found.

Alternatively, the solution algorithm described may be viewed as part of an expansion planning procedure that prescribes rules for interaction among generation planners. The procedure is divided into four distinct phases: a self-planning phase for each player; a communication phase between players; a re-optimization phase among players; and a termination phase in which a stable solution outcome is found. See Fig. 1. In the initial phase, the independent system operator (ISO) forecasts the load and determines the price it will offer for

\footnotetext{
${ }^{3}$ Inelastic demand evokes an inequality constraint since it can lead to a situation in which demand exceeds available supply. On the other hand, elastic demand would inevitably yield a point of intersection between market supply and demand curves. For example, in the case of elastic demand for energy intersection would occur at quantity $L_{t}$, in constraint (6), and (6) would take the form of an equality constraint. Thus, by choice of constraint type the proposed formulation can accommodate both cases of demand elasticity.
} 
TABLE I

EXISTING GENERATING UNITS

\begin{tabular}{l|l|l|l|l}
\hline $\begin{array}{l}\text { No. of } \\
\text { units }\end{array}$ & Technology & $\begin{array}{l}\text { Size } \\
\text { (MW) }\end{array}$ & $\begin{array}{l}\text { Operating } \\
\text { Cost } \\
\text { (\$/MWh) }\end{array}$ & $\begin{array}{l}\text { Forced } \\
\text { Outage } \\
\text { Rate }\end{array}$ \\
\hline \hline 1 & nuclear & 650 & 4 & .05 \\
\hline 1 & coal & 650 & 10 & .04 \\
\hline 1 & oil & 350 & 20 & .02 \\
\hline 2 & oil & 300 & 30 & .02 \\
\hline 1 & gas turbine & 200 & 50 & .01 \\
\hline
\end{tabular}

TABLE II

CANDIDATE EXPANSION UNITS

\begin{tabular}{l|l|l|l|l}
\hline Technology & $\begin{array}{l}\text { Maximum } \\
\text { Size } \\
\text { (MW) }\end{array}$ & $\begin{array}{l}\text { Operating } \\
\text { Cost } \\
\mathbf{( \$ / M W h )}\end{array}$ & $\begin{array}{l}\text { Forced } \\
\text { Outage } \\
\text { Rate }\end{array}$ & $\begin{array}{l}\text { Capital } \\
\text { Cost } \\
\mathbf{\$} / \mathbf{M W})\end{array}$ \\
\hline \hline coal & 650 & 15 & .04 & 650,000 \\
\hline oil & 350 & 25 & .02 & 500,000 \\
\hline gas turbine & 200 & 40 & .01 & 250,000 \\
\hline
\end{tabular}

capacity reserves. ${ }^{4}$ Afterwards the ISO broadcasts load and capacity price information to all players, who then individually form their own initial expansion plans that specify size of expansion for their plant technology. In the second phase, communication is exchanged between each player and the ISO. Players report their initial plans for expansion to the ISO, and the ISO broadcasts the information it receives to all players. In the third phase, one by one in rounds each player re-optimizes its expansion plan given all other players' updated expansion plans. For example, in the first round of the third phase an arbitrary player, say player A, updates its expansion plan knowing the plans of all other players. Player A then reports its updated plan to the ISO who transmits the information to the next player, B. Player B then re-optimizes its expansion plan and reports its updated plan to the ISO. The process repeats with each subsequent player remaining in the round. This phase of the algorithm iterates until no player alters its expansion plan for one entire round, after which the algorithm reaches phase four and terminates. Since the resulting solution vector of expansion decisions has the property that no player can improve its profit by changing its plan, the solution vector is a Cournot equilibrium.

\section{NUMERICAL RESULTS}

\section{A. Test System}

A numerical test system is adapted from [6]. There are six existing generating units in the system, all listed in Table I in order of increasing operating cost. Information on plant sizes, operating costs, and forced outage rates are also given in the table.

Candidate expansion units in the test system are listed in Table II. They consist of a coal-fired plant, an oil-fired plant, and

\footnotetext{
${ }^{4} \mathrm{~A}$ technique for determining the ideal price for capacity reserves from a social welfare perspective is discussed in [3].
}

a gas turbine unit (i.e., one base load unit, one cycling unit, and one peaking unit). Their maximum sizes, operating costs, capital costs, and forced outage rates are also included in the table. Each candidate expansion unit, or player, acts as an individual profit-maximizing entity in the generation expansion planning game. Also, to reduce the number of decision variables we only allow candidate expansion units to participate in the capacity reserve market in the test system.

For our numerical simulations in which demand is assumed inelastic, load is taken as the chronological load profile of the IEEE Reliability Test System (IEEE RTS) [10] with peak load of $2850 \mathrm{MW}$. In our final simulation set in which demand is assumed elastic, we represent demand by linear, decreasing inverse demand curves that have $y$-intercepts at $100 \$ / M W$ and slopes ranging from $-\frac{3}{25}$ to $-\frac{1}{57} \$ \mathrm{MW}^{2}$. The slopes were chosen so as to produce the IEEE RTS load duration curve when intersecting inverse demand curves with an industry supply curve derived from Cournot expansion under inelastic demand.

\section{B. Expansion Outcomes and Trends}

Expansion results for five different competitive scenarios among three candidate expansion units are presented in Table III. In the first scenario, Cournot competition, each generating unit acts independently to maximize its profit. In the second case, players collude by jointly maximizing profit in a cartel. The last three scenarios involve Cournot duopoly competition between a single player and a coalition comprised of the remaining players. In our example the coal plant is labeled unit 1, the oil-fired plant is labeled unit 2, and the gas turbine plant is labeled unit 3. Decision outcomes, resulting profits, and reserve margins (RM) for each competitive scenario are summarized in the table. The amount of reserve margin after expansion provides a deterministic indication of generation system adequacy. The table also shows probabilistic measures of adequacy such as expected unserved energy (EUE) and loss of load probability (LOLP). The dataset was gathered under the assumption of inelastic demand.

Comparing outcomes in Table III, notice that the formation of the grand coalition or cartel yields the greatest profit but lowest output; whereas Cournot competition yields least aggregate profit but greatest output. Moreover, duopoly outcomes fall in between cartel and Cournot outcomes. These results support theoretical predictions stemming from analysis of the classic Cournot model. Theory predicts total output increases and aggregate profit decreases as the number of noncolluding players in the industry increases [8].

Numerical results in Table III also indicate a direct correlation between total output and reliability, and an opposing relationship between profit and reliability. Namely, with greater total expansion generation system reliability improves in all reliability measures examined. Moreover, the greater the aggregate profit of players, the worse system reliability is. These patterns are consistent among all competitive scenarios listed. In particular, the formation of the grand coalition or cartel yields the greatest profit but worst reliability rating; whereas Cournot competition yields least aggregate profit but the best reliability rating. Duopoly outcomes fall in between cartel and Cournot outcomes, 
TABLE III

SUMMARY OF RESULTS FOR DIFFERENT COMPETITIVE SCENARIOS

\begin{tabular}{|c|c|c|c|c|c|c|c|c|c|c|c|c|}
\hline $\begin{array}{c}\text { Competitive } \\
\text { Scenario }\end{array}$ & $\begin{array}{c}\boldsymbol{x}_{\epsilon 1} \\
(\mathrm{MW})\end{array}$ & $\begin{array}{c}x_{e 2} \\
\text { (MW) }\end{array}$ & $\begin{array}{r}x_{c 3} \\
\text { (MW) }\end{array}$ & $\begin{array}{c}\boldsymbol{x}_{\boldsymbol{t}} \\
(\mathrm{MW})\end{array}$ & $\begin{array}{c}x_{v 2} \\
(\mathrm{MW})\end{array}$ & $\begin{array}{c}x_{n 3} \\
(\mathrm{MW})\end{array}$ & $\begin{array}{c}\text { profit, } \\
\text { (5) }\end{array}$ & $\begin{array}{l}\text { profit }_{2} \\
\text { (\$) }\end{array}$ & $\begin{array}{c}\text { profit, } \\
\text { (\$) }\end{array}$ & $\begin{array}{l}\text { KM } \\
\text { (F) }\end{array}$ & $\begin{array}{c}\text { EUE } \\
(\mathrm{MWh} / \mathrm{y})\end{array}$ & $\begin{array}{c}\text { LOL.P } \\
\text { (hrs/yr) }\end{array}$ \\
\hline Cournat & 310 & 109 & 136 & $\overline{73}$ & 10199 & 15 & $21.94 \mathrm{M}$ & $5.48 \mathrm{M}$ & $7.36 \mathrm{M}$ & & & \\
\hline Totals= & \multicolumn{3}{|c|}{555} & \multicolumn{3}{|c|}{$31 \mathrm{k}$} & \multirow{2}{*}{\multicolumn{3}{|c|}{$\frac{34.78 \mathrm{M}}{46.77 \mathrm{M}}$}} & $5 \%$ & 16,349 & 93 \\
\hline Cartel & 251 & 7 & 70 & 66 & 7 & 70 & & & & & 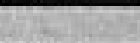 & \\
\hline Totals= & \multicolumn{3}{|c|}{328} & \multicolumn{3}{|c|}{143} & \multicolumn{3}{|c|}{$46.77 \mathrm{M}$} & -35 & 49,644 & 222 \\
\hline$\{1\} .\{23\}$ & 273 & 10 & 129 & 72 & 10 & 129 & $26.94 \mathrm{M}$ & joint & $16.82 \mathrm{M}$ & & & \\
\hline Totals $=$ & \multicolumn{3}{|c|}{412} & \multicolumn{3}{|c|}{211} & \multicolumn{3}{|c|}{$43.76 \mathrm{M}$} & $0.4 \%$ & 33,836 & 168 \\
\hline$\{2\},\{1,3\}$ & 272 & 119 & 63 & 72 & 119 & 63 & joint & $9.81 \mathrm{M}$ & $29.52 \mathrm{M}$ & & 20 & \\
\hline Totals= & \multicolumn{3}{|c|}{454} & \multicolumn{3}{|c|}{254} & \multicolumn{3}{|c|}{$39.33 \mathrm{M}$} & $2 \%$ & 27.586 & 143 \\
\hline$(3],\{1,2\rangle$ & 264 & 17 & 141 & 67 & 17 & 141 & joint & $28.25 \mathrm{M}$ & $14.96 \mathrm{M}$ & 6 & & \\
\hline Totals= & \multicolumn{3}{|c|}{422} & \multicolumn{3}{|c|}{225} & \multicolumn{3}{|c|}{$43.21 \mathrm{M}$} & $1 \%$ & 32.102 & 160 \\
\hline
\end{tabular}

TABLE IV

Average Costs of CANDIDATE Units IN COURNOT OUTCOME

\begin{tabular}{|c|c|c|c|c|c|}
\hline $\begin{array}{c}\text { Candidate } \\
\text { Expansion } \\
\text { Unit }\end{array}$ & $\mid \begin{array}{c}\text { Size } \\
(\mathrm{MW})\end{array}$ & $\begin{array}{c}\text { Operating } \\
\text { Cost } \\
(\$ / M W h)\end{array}$ & $\begin{array}{l}\text { Annual } \\
\text { Energy } \\
\text { (MWh) }\end{array}$ & $\begin{array}{c}\text { Capital } \\
\text { Cost } \\
(\$ / y r)\end{array}$ & $\begin{array}{c}\text { Average } \\
\text { Cost } \\
(\$ / \mathbf{M W h})\end{array}$ \\
\hline$\overline{\text { coal }}$ & 310 & 15 & $2,057,876$ & $7,807,745$ & 18.79 \\
\hline oil & 109 & 25 & 25,589 & $2,111,772$ & 107.53 \\
\hline gas tu & 136 & 40 & 0 & 1.317 .435 & infinity \\
\hline
\end{tabular}

with duopoly $\{2\},\{1,3\}$ achieving the greatest reliability rating but least profit among all duopolies. These trends suggest that players in collusion will collectively increase their profits at the expense of overall generation system adequacy.

Results also show cartel expansion produced a negative reserve margin. That is, total expansion by the cartel fell below peak demand, illustrating an instance when players would find it profitable to under-expand. This example points to the possibility that firms with monopoly-like power may opt to under-expand in a situation of inelastic demand, thereby degrading reliability of the generation supply system.

\section{Average Costs}

Table III reveals in all scenarios candidate players 2 and 3 devote their entire plant capacity to supplying reserves in the capacity reserve market; whereas player 1 offers only a portion of its capacity to the reserve market. We investigate a possible explanation for these outcomes by examining average costs of each candidate expansion unit and comparing costs against average energy market clearing prices (MCPs) in each scenario.

Average cost of a generating unit is equal to its capital cost per unit of energy production plus its operating cost. This cost may be computed according to the following expression: average cost $=$ opcost $+($ capital cost/annual energy $)$, where opcost is the plant's operating cost, capital cost is its annualized capital construction cost, and annual energy is its combined energy and real-time market production.

To illustrate how average cost is computed, data comprising average cost calculations for one competitive scenario is provided in Table IV. In the table, the gas turbine unit's average
TABLE V

Average Cost and Price Comparisons Between Different COMPETITIVE SCENARIOS

\begin{tabular}{|c|c|c|c|c|c|}
\hline $\begin{array}{c}\text { Competitive } \\
\text { Scenario }\end{array}$ & $\mid \begin{array}{c}\text { Avg Cost } \\
\text { of coal unit } \\
(\$ / M W h)\end{array}$ & $\begin{array}{l}\text { Avg Cost } \\
\text { of oil unit } \\
(\$ / M W h)\end{array}$ & $\begin{array}{c}\text { Avg Cost } \\
\text { of gas unit } \\
(\$ / M W h)\end{array}$ & $\begin{array}{c}\text { Avg } \\
\text { MCP } \\
\$ / M W h\end{array}$ & $\begin{array}{c}\text { Avg } \\
\text { RTP } \\
\text { \$/MWh }\end{array}$ \\
\hline Cournot & 18.79 & 107.53 & infinity & 21.95 & 18.69 \\
\hline Cartel & 18.69 & 30.17 & 169.73 & 23.01 & 22.64 \\
\hline$\{1\},\{2,3\}$ & 18.74 & 33.00 & 835.41 & 22.69 & 19.97 \\
\hline$\{2\},\{1,3\}$ & 18.74 & 110.76 & infinity & 22.71 & 18.92 \\
\hline$\{3\},\{1,2\}$ & 18.71 & 32.48 & 1664.51 & 22.77 & 20.57 \\
\hline
\end{tabular}

cost is infinity since its annual energy production is zero. Note that the gas turbine unit receives revenue only from the capacity reserve market.

For each competitive scenario, Table $\mathrm{V}$ summarizes average costs of each candidate expansion unit along with average market clearing prices in both the energy and real-time markets. The table reveals that average cost of the coal unit is less than the average MCP; whereas average costs of the oil and gas turbine units are higher than the average MCP in every scenario. High average costs of oil and gas turbine plants compared to the average MCP imply these plants would receive insufficient revenue from participation in the energy market. Compensation incurred from their participation would fall short of their production and capital costs. On the other hand, payments from capacity reserve contracts could well exceed each player's average cost. Therefore, the oil and gas plants which have high average costs commit their entire capacity to the capacity reserve market. Thus these units receive their bulk of revenues in the form of capacity reserve payments. As was the trend for profit, average MCP is highest under cartel expansion and lowest under Cournot competition, with MCPs resulting from duopoly cases falling in between these two extremes. Similar trends involving average RTP's can be observed from Table V. Since MCP and RTP reflect prices at which buyers purchase electricity, numerical results indicate customers are best off when generation expanders face Cournot competition and worst off when they collude in a cartel. This 


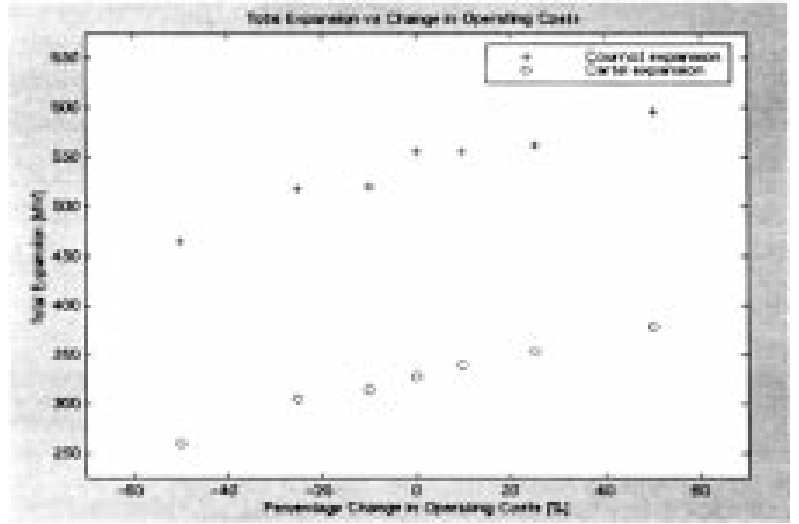

Fig. 2. Expansion results with change in operating cost.

conclusion is also supported by predictions of microeconomic theory.

An unexpected result can be noted in Table V. Namely, average RTP is less than average MCP in all scenarios. If real markets are any reflection, one would expect RTP to exceed MCP on average, as has been the case involving California's energy balancing market. A reversal in results may be explained by how real-time demand is determined in our mathematical model, as revealed by constraint (8). We approximate real-time energy demand as the amount of remedial energy needed to cover forced outages of units scheduled in the energy market. So no other sources of demand forecast errors, such as strategic behavior of energy market participants, are considered. Strategic behavior occurs when participants purposely deviate from scheduled energy commitments in hopes of increasing profit by relying on real-time market prices. Such deviations from scheduled energy in reality may significantly boost real-time demand and drive up RTP. However, to retain a simpler model we did not consider other factors of uncertainty influencing real-time demand besides plant outages [although other factors may be considered by adding terms to the right hand side of constraint (8)]. So real-time demand is only a fraction of scheduled energy in our model. Thus numerical results showing MCPs that exceed RTPs are consistent with our model.

\section{Expansion With Change in Operating Cost}

Fig. 2 displays expansion outcomes given various percent changes in operating costs for the Cournot and cartel scenarios. The figure illustrates that as operating cost increases total expansion also increases. Also, cartel expansion remains less than aggregate expansion by Cournot players despite changes in operating costs.

\section{E. Probabilistic Reliability Improvement}

Next we examine the cartel's output decision under a regulatory obligation to meet a pre-established minimum reserve margin requirement. Such a criterion is analogous to the traditional electric utility's obligation to serve. In our example, the minimum reserve margin imposed on the cartel is set equal to the reserve margin resulting from Cournot competition under inelastic demand.

Table VI compares output decisions of the constrained cartel with those of Cournot players. Numerical results indicate that although reserve margins are identical, the Cournot solution improves reliability probabilistically over the cartel outcome. EUE and LOLP are common probabilistic measures of generation system reliability. Unlike reserve margin computations, EUE and LOLP take into account sizes and forced outage rates of units that comprise the generating system. Because Cournot expansion produces a more even spread of capacity construction among the three candidate technologies, Cournot expansion leads to improved probabilistic reliability ratings compared to traditional utility expansion with an equivalent reserve margin requirement. So results suggest competition in generation expansion may improve reliability.

\section{F. Outcomes Under Elastic Demand}

Outcomes of the test system under an assumption of elastic demand are presented in this subsection. A collection of 8760 hourly inverse demand curves that vary as described in Section V-A are modeled and outcomes for a few scenarios of competition are summarized in Table VII. The first row of Table VII presents social welfare maximizing decisions of each player. By definition, the social welfare maximizing solution benefits society above all other expansion plans. Welfare is the difference between benefit of electricity use to consumers and total cost of providing electric service to suppliers [1, p. 33]. Hourly benefit can be computed by integrating the area under the inverse demand curve up to the quantity of load at the specified hour. So total benefit to consumers is computed from summing these areas under each hourly inverse demand curve in the planning period.

Results from simulating Cournot and cartel competition are also summarized in Table VII. Unlike the cartel and welfare maximizing solutions which are unique, different Cournot solutions were discovered over the course of many algorithm runs. None of the Cournot solutions found, however, dominate any other. They are pareto-optimal since each player favors a different Cournot solution. Interestingly enough, each Cournot solution shares the same aggregate expansion and capacity reserve totals. Furthermore, Cournot aggregate expansion falls between that resulting from social welfare maximization and cartel profit maximization, as expected from theory. Moreover, the social welfare maximizing solution yields greatest expansion, while the cartel solution yields least expansion but most profit. This trend also adheres to theoretical predictions from classic oligopoly theory.

\section{TheORETICAL RESULtS}

Although classic Cournot oligopoly theory does not strictly apply to GEP due to the constraints found in our model, several results have been extended to a subclass of GEP games formulated. Reference [2] details our development of analytical proofs that compare outcomes of Cournot competition in GEP to that 
TABLE VI

COURNot EXPANSION Versus CARTEl EXPANSION With Minimum RESERVE MARGIN REQUiREMENT

\begin{tabular}{|c|c|c|c|c|c|c|c|c|c|c|c|c|}
\hline $\begin{array}{c}\text { Competitive } \\
\text { Scenario }\end{array}$ & $\begin{array}{c}x_{c 1} \\
(M W)\end{array}$ & $\begin{array}{c}x_{c 2} \\
(M W)\end{array}$ & $\begin{array}{c}x_{c 3} \\
(M W)\end{array}$ & $\begin{array}{c}x_{01} \\
\text { (MW) }\end{array}$ & $\begin{array}{c}x_{o 2} \\
\text { (MW) }\end{array}$ & $\begin{array}{c}x_{03} \\
\text { (MW) }\end{array}$ & $\begin{array}{c}\text { profit }_{1} \\
(\$)\end{array}$ & $\begin{array}{c}\text { profit } \\
(\$)\end{array}$ & $\begin{array}{c}\text { profit }_{3} \\
(\$)\end{array}$ & $\begin{array}{l}\text { RM } \\
(\%)\end{array}$ & $\begin{array}{c}\text { EUE } \\
(\mathbf{M W h} / \mathbf{y r})\end{array}$ & $\begin{array}{c}\text { LOLP } \\
\text { (hrs/yr) }\end{array}$ \\
\hline$\overline{\overline{\text { Cournot }}}$ & 3 & $\overline{109}$ & $\overline{136}$ & 73 & 109 & 136 & $21.94 \mathrm{M}$ & $5.48 \mathrm{M}$ & $7.36 \mathrm{M}$ & & 18 & \\
\hline Totals $=$ & & 555 & & & 318 & & & $34.78 \mathrm{M}$ & & $5.4 \%$ & 16,349 & 93 \\
\hline Cartel w/ RM & 397 & 7 & 151 & 73 & 6 & 87 & & $42.68 \mathrm{M}$ & & 7>:-2: & & \\
\hline Totals $=$ & & 555 & & & 166 & & & $42.68 \mathrm{M}$ & & $5.4 \%$ & 17,300 & 96 \\
\hline
\end{tabular}

TABLE VII

SUMMARY OF RESULTS UNDER ELASTIC DEMAND

\begin{tabular}{|c|c|c|c|c|c|c|c|c|c|}
\hline $\begin{array}{l}\text { Competitive } \\
\text { Scenario }\end{array}$ & $\begin{array}{l}x_{c 1} \\
\text { MW }\end{array}$ & $\begin{array}{l}x_{c 2} \\
M W\end{array}$ & $\begin{array}{l}x_{c 3} \\
\mathbf{M W}\end{array}$ & $\begin{array}{l}x_{p 1} \\
\text { MWW }\end{array}$ & $\begin{array}{l}x_{02} \\
M W\end{array}$ & $\begin{array}{l}x_{\theta 3} \\
\mathbf{M W}\end{array}$ & $\underset{(\$)}{\text { profit }_{1}}$ & $\underset{(\$)}{\text { profit }}$ & $\begin{array}{c}\text { profit }_{3} \\
(\$)\end{array}$ \\
\hline$\overline{\text { Social welfare }}$ & 427 & 0 & 191 & $\overline{0}$ & 0 & 143 & $-3.94 \mathrm{M}$ & 0 & $26.34 \mathrm{M}$ \\
\hline Totals $=$ & \multicolumn{3}{|c|}{618} & \multicolumn{3}{|c|}{143} & \multicolumn{3}{|c|}{$22.40 \mathrm{M}$} \\
\hline Cournot A & 155 & 107 & 141 & 90 & 107 & 141 & $3.61 \mathrm{M}$ & $3.97 \mathrm{M}$ & $6.59 \mathrm{M}$ \\
\hline Totals= & \multicolumn{3}{|c|}{403} & \multicolumn{3}{|c|}{338} & \multicolumn{3}{|c|}{$14.17 \mathrm{M}$} \\
\hline Cournot B & 154 & 114 & 135 & 89 & 114 & 135 & $3.58 \mathrm{M}$ & $4.23 \mathrm{M}$ & $6.31 \mathrm{M}$ \\
\hline Totals $=$ & \multicolumn{3}{|c|}{403} & \multicolumn{3}{|c|}{338} & \multicolumn{3}{|c|}{$14.12 \mathrm{M}$} \\
\hline Cournot C & 154 & 116 & 133 & 89 & 116 & 133 & $3.58 \mathrm{M}$ & $4.30 \mathrm{M}$ & $6.22 \mathrm{M}$ \\
\hline Totals= & \multicolumn{3}{|c|}{403} & \multicolumn{3}{|c|}{338} & \multicolumn{3}{|c|}{$14.10 \mathrm{M}$} \\
\hline Cartel & 64 & 0 & 143 & 0 & 0 & 143 & $0.77 \mathrm{M}$ & 0 & $26.72 \mathrm{M}$ \\
\hline Totals= & \multicolumn{3}{|c|}{207} & \multicolumn{3}{|c|}{143} & \multicolumn{3}{|c|}{$27.49 \mathrm{M}$} \\
\hline
\end{tabular}

of cartel expansion in terms of total capacity output, reserve margin, and incentive to introduce new technologies. Analytical results in the work include:

- Cournot exceeds cartel expansion in total output.

- Cournot exceeds cartel expansion in reserve margin.

- Cournot expansion after introduction of new technology is no less than monopoly expansion.

That is, we have proven that under certain assumptions industry expansion and reserve margin resulting from Cournot competition is higher than those resulting from joint-profit maximization by a cartel. We have also proven that total expansion by Cournot players after introduction of new technology is no less than monopoly expansion. Such a result implies that a monopoly may lack sufficient incentive to introduce new technologies. See [2] for more details on conclusions, proofs, and assumptions.

\section{CONCLUSION}

Electric power industry restructuring has introduced new questions and concerns in power systems planning. Primary questions in the debate include: what is the best way to restructure the industry; what are the economic justifications; and does competition improve or compromise reliability? Our work offers a inter-disciplinary approach toward addressing such questions prevalent during industry restructuring. We address the need for a theoretically well-founded methodology for studying generation expansion in the context of a competitive electric power industry. In particular, we formulate a game that can be used to study expansion planning in competitive environments dominated by auction markets. And we verify expansion outcomes and trends identified from numerical application of our model support popular economic beliefs regarding the merits of increased competition. Merits that were identified include greater industry expansion, lower prices, and higher reliability in certain cases of oligopoly competition compared to cartel expansion. The proposed methodology may find application by planning engineers or regulators seeking to analyze system-wide generation expansion.

\section{REFERENCES}

[1] R. Bohn, M. Caramanis, R. Tabors, and F. Schweppe, Spot Pricing of Electricity. Boston: Kluwer Academic Publishers, 1988.

[2] A. Chuang, "Generation expansion planning in a competitive electric power industry," Ph.D. dissertation, Department of Electrical Engineering and Computer Science, UC Berkeley, Fall 1999.

[3] A. Chuang and F. Wu, "Capacity payments and the pricing of reliability in competitive generation markets," in Proceedings of the Hawaii International Conference on System Sciences, Maui, Jan. 2000.

[4] A. Cournot, Researches Into the Mathematical Principles of the Theory of Wealth. New York: Macmillan, 1897. Translated by Nathaniel Bacon.

[5] T. Gonen, Modern Power System Analysis. New York: John Wiley \& Sons, 1988

[6] Y. Q. He and A. K. David, "Advances in global optimization for generation expansion planning," IEE Proceedings on Generation, Transmission, and Distribution, vol. 142, no. 4, pp. 423-428, July 1995.

[7] D. M. Kreps and J. A. Scheinkman, "Quantity precommitment and Bertrand competition yield Cournot outcomes," The Bell Journal of Economics, vol. 14, pp. 326-337, 1983.

[8] J. Tirole, The Theory of Industrial Organization. Cambridge: The MIT Press, 1988.

[9] W. J. Yuan and Y. Smeers, "Spatial oligopolistic electricity models with Cournot generators and regulated transmission prices," Operations Research, vol. 47, no. 1, pp. 102-112, Jan.-Feb. 1999.

[10] Reliability Test System Task Force, "IEEE Reliability Test System," IEEE Trans. Power Apparatus and Systems, vol. PAS-98, no. 6, pp. 2047-2054, Nov./Dec. 1979.

Angela S. Chuang received the B.S., M.S., and Ph.D. degrees in electrical engineering and computer science at UC Berkeley in 1992, 1995, and 1999, respectively. She is currently a visiting postdoctoral research engineer at the same institution. Her research interests include power systems restructuring and reliability.

Felix Wu received the Ph.D. degree from UC Berkeley, where he is currently a professor of Electrical Engineering and Computer Science, on leave at the University of Hong Kong. Dr. Wu is a Fellow of IEEE.

Pravin Varaiya received the Ph.D. degree from UC Berkeley, where he is currently a professor of Electrical Engineering and Computer Science. Dr. Varaiya is a Fellow of IEEE. 